\title{
Swarm intelligence based State-of-Charge optimization for charging Plug-in Hybrid Electric Vehicles
}

\author{
I. Rahman ${ }^{1}$, P. M. Vasant ${ }^{1}$, B. S. M. Singh ${ }^{1}$ \\ \& M. Abdullah-Al-Wadud ${ }^{2}$ \\ ${ }^{1}$ Department of Fundamental and Applied Sciences, \\ Universiti Teknologi PETRONAS, Malaysia \\ ${ }^{2}$ Department of Software Engineering, King Saud University, KSA
}

\begin{abstract}
Transportation electrification has undergone major changes since the last decade. Success of the smart grid with renewable energy integration solely depends upon the large-scale penetration of Plug-in Hybrid Electric Vehicles (PHEVs) for a sustainable and carbon-free transportation sector. One of the key performance indicators in the hybrid electric vehicle is the State-of-Charge (SoC), which needs to be optimized for the betterment of charging infrastructure using stochastic computational methods. In this paper, a newly emerged accelerated particle swarm optimization (APSO) technique was applied and compared with standard Particle swarm optimization (PSO), considering charging time and battery capacity. Simulation results obtained for maximizing the highly non-linear objective function indicate that APSO achieves some improvement in terms of best fitness and computation time.

Keywords: Plug-in Hybrid Electric Vehicles, charging infrastructures, optimization, swarm intelligence, smart grid, battery capacity, State-of-Charge, charging efficiency, particle swarm optimization, accelerated particle swarm optimization.
\end{abstract}

\section{Introduction}

The vehicular network recently accounts for around $25 \%$ of $\mathrm{CO}_{2}$ emissions and over $55 \%$ of oil consumption around the world [1]. $\mathrm{CO}_{2}$ is the primary greenhouse gas emitted through human activities such as combustion of fossil fuels (coal, 
natural gas, and oil) for energy and transportation. Several researchers have proved that a great amount of reductions in greenhouse gas emissions and the increasing dependence on oil could be accomplished by electrification of transport sector [2]. Indeed, the adoption of hybrid electric vehicles (HEVs) has brought significant market success over the past decade. Vehicles can be classified into three groups: internal combustion engine vehicles (ICEV), hybrid electric vehicles (HEV) and all-electric vehicles (AEV) [3]. Plug-in Hybrid Electric Vehicles (PHEVs) have very recently been introduced with a promise to boost up the overall fuel efficiency by holding a higher capacity battery system, which can be directly charged from conventional power grid system, helping the vehicles to operate continuously in "all-electric-range" (AER). An all-electric vehicle or AEV is a vehicle using electric power as the only source to move the vehicle [4]. PHEVs with a connection to the smart grid can own all of these strategies. Hence, the widely extended adoption of PHEVs might play a significant role in the alternative energy integration into traditional grid systems [5]. There is a need of efficient mechanisms and algorithms for smart grid technologies in order to solve highly diverse problems like energy management, cost reduction, efficient charging infrastructure etc. with different objectives and system constraints [6].

According to the statistics of Electric Power Research Institute (EPRI), about $62 \%$ of US vehicles will comprise PHEVs within the year 2050 [7]. Moreover, there is an increasing demand to implement this technology on the electric grid system. Large numbers of PHEVs have the capability to make threats to the stability of the power system. For example, in order to avoid disturbance when several thousand PHEVs are introduced into the system over a small period of time, the load on the power grid will need to be managed very carefully. One of the main targets is to facilitate the proper communication between the power grid and the PHEV. For the maximization of customer contentment and minimization of burdens on the grid, a complicated control appliance will need to be addressed in order to govern multiple battery loads from a numbers of PHEVs properly [8]. The total demand pattern will also have an important impact on the electricity production due to differences in the needs of the PHEVs parked in the deck at certain time [9]. Proper management can ensure strain minimization of the grid and enhance the transmission and generation of electric power supply. The control of PHEV charging depending on the locations can be classified into two groups; household charging and public charging. The proposed optimization focuses on the public charging station for plug-in vehicles because most of PHEV charging is expected to take place in public charging locations [10].

Wide penetration of PHEVs in the market depends on a well-organized charging infrastructure. The power demand from this new load will put extra stress on the traditional power grid [12]. As a result, a good number of PHEV charging infrastructures with suitable facilities are essential to be built for recharging electric vehicles, for this some strategies have been proposed by the researchers $[13,14]$. Charging stations are needed to be built at workplaces, markets/shopping malls and home. Boyle [15] proposed the necessity of building new smart charging station with effective communication among utilities along with sub-station control infrastructure in view of grid stability and proper energy utilization. 
Furthermore, sizeable energy storage, cost minimization; Quality of Services (QoS) and optimal power of intelligent charging station are underway [16]. Thus, the evolution of a reliable, efficient, robust and economical charging infrastructure is underway. In this wake, numerous techniques and methods have been proposed for the deployment of a charging station for PHEVs [17].

One of the important constraints for accurate charging is State-of-Charge (SoC). The charging algorithm can be carefully managed by the precise state of charge evaluation [11]. An approximate graph of a typical Lithium-ion cell voltage versus SoC is shown in Fig. 1. The figure indicates that the slope of the curve below $20 \%$ and above $90 \%$ is high enough to result in a significant voltage difference to be depended on by measurement circuits and charge balancing control. There is the need for an in-depth study on the maximization of average SoC in order to facilitate intelligent energy allocation for PHEVs in a charging station. Accelerated PSO was developed by Xin-She Yang [18] at Cambridge University in 2007 in order to accelerate the convergence of the algorithm, to create the best one that can be used globally.

PSO- and APSO-based optimizations have already been studied by researchers for the optimal design of a substation grounding grid [19], non-convex optimization [20, 21], performance analysis of MIMO radar waveform [22], design of frame structures [23], dual channel speech enhancement [24], synthesis gas production [25] and a faster path planner [26]. Specifically, we are investigating the use of the accelerated particle swarm optimization (APSO) method for developing real-time and large-scale optimizations for allocating power.

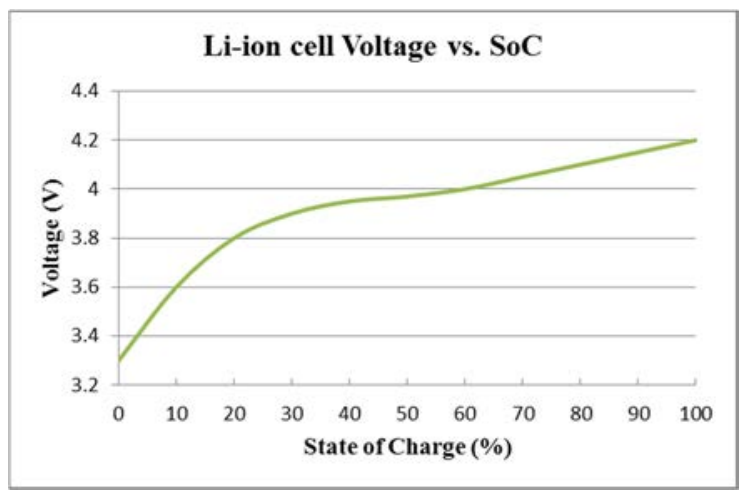

Figure 1: Li-ion cell voltage vs. State-of-Charge [27].

The remainder of this paper is organized as follows: the next section will describe the specific problem that we are trying to solve. We will provide the optimization objective and constraints, mathematical formulation of our algorithm and review the APSO method as well as describe how the algorithm works for our optimization problems. The simulation results and analysis are then presented with an extensive comparison with standard PSO. Finally, conclusions and future directions are drawn. 


\section{Problem formulation}

The idea behind smart charging is to charge the vehicle when it is most favourable, which could be when electricity price and demand is lowest, and when there is excess capacity [6].

Suppose there is a charging station with the capacity of total power P. Total N numbers of PHEVs need to be served in a day (24 hours). The proposed system should allow PHEVs to leave the charging station before their expected leaving time for making the system more effective. It is worth to mention that, each PHEV is regarded to be plugged-in to the charging station once. The main aim is to allocate power intelligently for each PHEV coming to the charging station. The State-of-Charge is the main parameter which needs to be maximized in order to allocate power efficiently. For this, the objective function considered in this paper is the maximization of average SoC and thus allocate energy for PHEVs at the next time step. The constraints considered are: charging time, present SoC and price of the energy [8].

The objective function is defined as:

$$
\begin{gathered}
\operatorname{Max}_{1}(\mathrm{k})=\sum_{\mathrm{i}} \mathrm{w}_{\mathrm{i}}(\mathrm{k}) \operatorname{SoC}_{\mathrm{i}}(\mathrm{k}+1) \\
\mathrm{w}_{\mathrm{i}}(\mathrm{k})=\mathrm{f}\left(\mathrm{C}_{\mathrm{r}, \mathrm{i}}(\mathrm{k}), \mathrm{T}_{\mathrm{r}, \mathrm{i}}(\mathrm{k}), \mathrm{D}_{\mathrm{i}}(\mathrm{k})\right) \\
\mathrm{C}_{\mathrm{r}, \mathrm{i}}(\mathrm{k})=\left(1-\operatorname{SoC}_{\mathrm{i}}(\mathrm{k})\right) * \mathrm{C}_{\mathrm{i}}
\end{gathered}
$$

where $\mathrm{C}_{\mathrm{r}, \mathrm{i}}(\mathrm{k})$ is the battery capacity (remaining) needed to be filled for $\mathrm{i}$ no. of PHEV at time step $\mathrm{k}$; $\mathrm{C}_{\mathrm{i}}$ is the battery capacity (rated) of the $\mathrm{i}$ no. of PHEV; remaining time for charging a particular PHEV at time step $\mathrm{k}$ is expressed as $\mathrm{T}_{\mathrm{r}, \mathrm{i}}(\mathrm{k})$; the price difference between the real-time energy price and the price that a specific customer at the i no. of PHEV charger is willing to pay at time step k is presented by $\mathrm{D}_{\mathrm{i}}(\mathrm{k}) ; \mathrm{w}_{\mathrm{i}}(\mathrm{k})$ is the charging weighting term of the $\mathrm{i}$ no. of PHEV at time step $\mathrm{k}$ (a function of charging time, present SoC and price of the energy); $\mathrm{SoC}_{\mathrm{i}}(\mathrm{k}+1)$ is the state of charge of the $\mathrm{i}$ no. of PHEV at time step $\mathrm{k}+1$.

Here, the weighting term indicates a bonus proportional to the attributes of a specific PHEV. For example, if a PHEV has a lower initial SoC and less charging time (remaining), but the driver is eager to pay a higher price, the system will provide more power to this particular PHEV battery charger:

$$
\mathrm{w}_{\mathrm{i}}(\mathrm{k}) \alpha\left[\operatorname{Cap}_{\mathrm{r}, \mathrm{i}}(\mathrm{k})+\mathrm{D}_{\mathrm{i}}(\mathrm{k})+1 / \mathrm{T}_{\mathrm{r}, \mathrm{i}}(\mathrm{k})\right]
$$

The charging current is also assumed to be constant over $\Delta t$.

$$
\begin{gathered}
{\left[\operatorname{SoC}_{\mathrm{i}}(\mathrm{k}+1)-\operatorname{SoC}_{\mathrm{i}}(\mathrm{k})\right] \cdot \operatorname{Cap}_{\mathrm{i}}=\mathrm{Q}_{\mathrm{i}}=\mathrm{I}_{\mathrm{i}}(\mathrm{k}) \Delta \mathrm{t}} \\
\operatorname{SoC}_{\mathrm{i}}(\mathrm{k}+1)=\operatorname{SoC}_{\mathrm{i}}(\mathrm{k})+\mathrm{I}_{\mathrm{i}}(\mathrm{k}) \Delta \mathrm{t} / \operatorname{Cap}_{\mathrm{i}}
\end{gathered}
$$

where the sample time $\Delta \mathrm{t}$ is defined by the charging station operators, and $\mathrm{I}_{\mathrm{i}}(\mathrm{k})$ is the charging current over $\Delta \mathrm{t}$. 
The battery model is regarded as a capacitor circuit, where $\mathrm{C}_{\mathrm{i}}$ is the capacitance of battery (Farad). The model is defined as

$$
C_{i} \cdot \frac{d V_{i}}{d t}=I_{i}
$$

Therefore, over a small time interval, one can assume the change of voltage to be linear

$$
\begin{aligned}
& \mathrm{C}_{\mathrm{i}} \cdot\left[\mathrm{V}_{\mathrm{i}}(\mathrm{k}+1)-\mathrm{V}_{\mathrm{i}}(\mathrm{k})\right] / \Delta \mathrm{t}=\mathrm{I}_{\mathrm{i}} \\
& \mathrm{V}_{\mathrm{i}}(\mathrm{k}+1)-\mathrm{V}_{\mathrm{i}}(\mathrm{k})=\mathrm{I}_{\mathrm{i}} \Delta \mathrm{t} / \mathrm{C}_{\mathrm{i}}
\end{aligned}
$$

As the decision variable used here is the allocated power to the PHEVs, by replacing $I_{i}(k)$ with $P_{i}(k)$ the objective function finally becomes:

$$
\mathrm{J}(\mathrm{k})=\sum_{\mathrm{i}} \mathrm{w}_{\mathrm{i}} \cdot\left[\mathrm{SoC}_{\mathrm{i}}(\mathrm{k})+\frac{2 \mathrm{P}_{\mathrm{i}}(\mathrm{k}) \Delta \mathrm{t}}{0.5 \cdot \mathrm{C}_{\mathrm{i}} \cdot\left[\sqrt{\frac{2 \mathrm{P}_{\mathrm{i}}(\mathrm{k}) \Delta \mathrm{t}}{\mathrm{C}_{\mathrm{i}}}+\mathrm{V}^{2}{ }_{\mathrm{i}}(\mathrm{k})+\mathrm{V}_{\mathrm{i}}(\mathrm{k})}\right]}\right]
$$

The power obtained from the utility $\left(\mathrm{P}_{\mathrm{utility}}\right)$ and the maximum power $\left(\mathrm{P}_{\mathrm{i}, \mathrm{max}}\right)$ absorbed by a specific PHEV are the primary energy constraints being considered in this paper. The overall charging efficiency of a particular charging infrastructure is described by $\eta$. From the system point of view, charging efficiency is supposed to be constant at any given time step. Maximum battery SoC limit for the i no. of PHEV is $S_{0} C_{i, \text { max }}$. When $S_{0} C_{i}$ reaches the values close to $S_{0} C_{i, \max }$, the $i$ no. of battery charger shifts to a standby mode. The state of charge ramp rate is confined within limits by the constraint $\Delta \mathrm{SoC}_{\max }$. The overall control system is changed the state when i) system utility data updates; ii) a new PHEV is pluggedin; iii) time period $\Delta \mathrm{t}$ has periodically passed.

\section{Accelerated particle swarm optimization}

In APSO, each member of the population is called a particle and the population is called a swarm. Starting with a randomly initialized population and moving in randomly chosen directions, each particle moves through the searching space and remembers the best earlier positions, velocity and accelerations of itself and its neighbours. Particles of a swarm communicate good position, velocity and acceleration to each other as well as dynamically adjust their own position, velocity and acceleration derived from the best position of all particles. The next step starts when all particles have been shifted. Finally, all particles inclined to fly towards better positions over the searching process until the swarm move to close to an optimum of the fitness function. Fig. 2 shows the flowchart of APSO method. The standard PSO uses both the current global best $\mathrm{g}^{*}$ andthe individual best $\mathrm{x}_{\mathrm{i}}^{\mathrm{t}}$. The reason of using the individual best is mainly to increase the diversity in the 
quality solutions; however, this diversity can be simulated using some randomness. Subsequently, there is no convincing reason for using the individual best, unless the optimization problem of interest is multimodal and highly nonlinear [24].

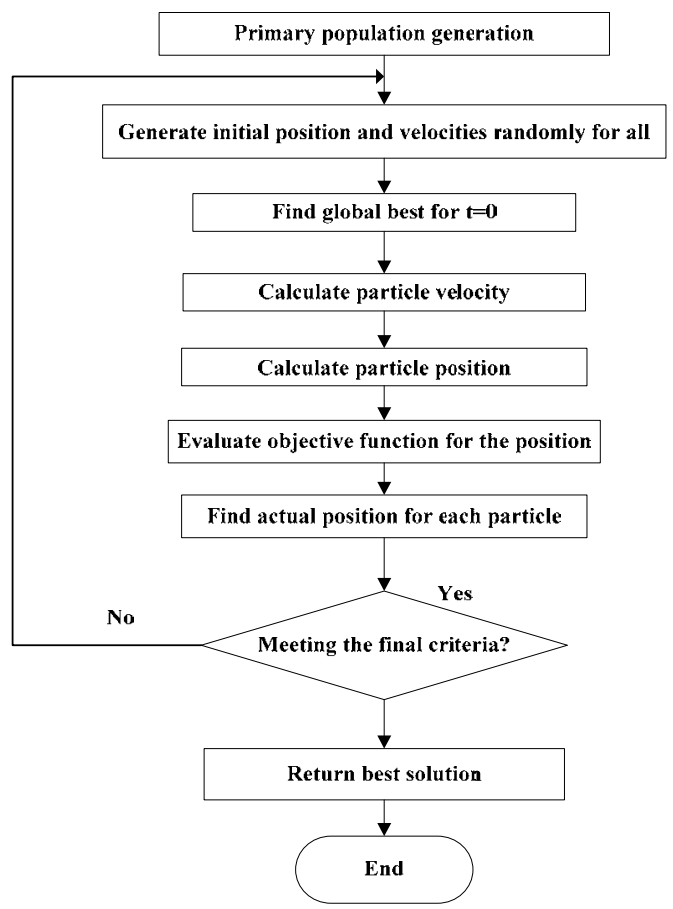

Figure 2: Flow chart of accelerated particle swarm optimization (APSO).

A simplified version, which could accelerate the convergence of the algorithm is to use the global best only. Thus, in the APSO [23], the velocity vector is generated by a simpler formula as where randn is drawn from $(0,1)$ to replace the second term. The update of the position is simply like (12).

$$
\begin{gathered}
V_{i}^{t+1}=V_{i}^{t}+\alpha \cdot \operatorname{randn}(t)+\beta \cdot\left(g^{*}-x_{i}^{t}\right) \\
x_{i}^{t+1}=(1-\beta) x_{i}^{t}+\beta g^{*}+\alpha r \\
\alpha=0.7^{t}
\end{gathered}
$$

In order to increase the convergence even further, we can also write the update of the location in a single step, as this simpler version will give the same order of convergence. The typical values for this accelerated PSO are $\alpha \approx$ $0.1 \sim 0.4$ and $\beta \approx 0.1 \sim 0.7$; however, $\alpha \approx 0.2$ and $\beta \approx 0.5$ are recommended [19]. The parameter settings for APSO are demonstrated in table 1. 
Table 1: APSO parameter settings.

\begin{tabular}{|l|c|}
\hline Parameters & Values \\
\hline Size of the swarm & 100 \\
\hline Maximum no. of steps & 100 \\
\hline Alpha, $\alpha$ & 0.2 \\
\hline Beta, $\beta$ & 0.5 \\
\hline Maximum iteration & 100 \\
\hline Number of runs & 30 \\
\hline
\end{tabular}

\section{Simulation results and analysis}

\subsection{Results}

The APSO and PSO algorithm were applied to find out global best fitness of the objective function. All the simulations were run on a Core ${ }^{\mathrm{TM}}$ i5-3470M CPU@ 3.20 GHz processor, 4.00 GB RAM and MATLAB R2013a.

Table 2 summarizes the simulation results for 50, 100, 500 and 1000 PHEVs respectively for finding the maximum fitness value of objective function $\mathrm{J}(\mathrm{k})$. In order to evaluate the performance and show the efficiency and superiority of the proposed algorithm, we ran each scenario total 30 times.

So it can be concluded that, APSO outperformed PSO in terms of Average best fitness. Starting from 50 numbers of PHEVs up to 1000 PHEVs, APSO shows better fitness value than PSO.

Table 2: Average best fitness for APSO and PSO.

\begin{tabular}{|l|c|c|}
\hline Average Best Fitness for & PSO & APSO \\
\hline 50 PHEVs & 142.839 & 165.96509 \\
\hline 100 PHEVs & 171.102 & 182.93134 \\
\hline 500 PHEVs & 150.869 & 197.59083 \\
\hline 1000 PHEVs & 156.802 & 172.45284 \\
\hline
\end{tabular}

Table 3 shows the computational time requirement for APSO and PSO method. As the number of PHEVs increased from 100 to 500 and 1000, APSO technique shows better result than standard PSO method in terms of computational time.

Fig. 3 shows the convergence behaviour (iteration vs. fitness value) of APSO technique. It can be apparently seen that although the algorithm has been set to run for maximum 100 iterations, the fitness value converges after 10 iterations and become stable. So, there is an early convergence which may cause the fitness function to trap into local minima. This can be avoided by increasing the size of swarm hence the computational time will also be increased as well. As a result, a trade-off should be taken into consideration between the proper convergence and computational time. 
Table 3: Computational time for APSO and PSO.

\begin{tabular}{|l|c|c|}
\hline Computational Time (sec.) & PSO & APSO \\
\hline 50 PHEVs & 1.650 & 1.685 \\
\hline 100 PHEVs & 1.686 & 1.690 \\
\hline 500 PHEVs & 1.990 & 1.856 \\
\hline 1000 PHEVs & 2.398 & 2.141 \\
\hline
\end{tabular}

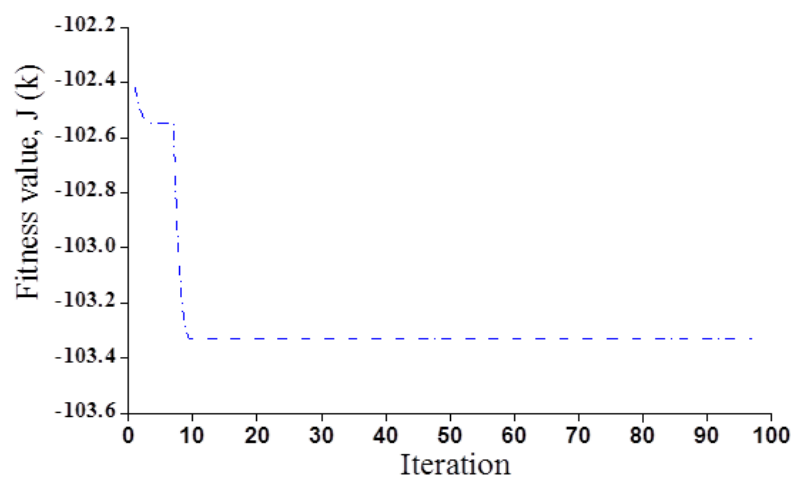

Figure 3: Iteration vs. fitness value, J (k) for APS (100 PHEVs).

\subsection{Comparison between PSO and APSO}

Table 4 illustrates the advantages and disadvantages of both APSO and PSO techniques for solving various optimization problems.

Table 4: Advantages and disadvantages of PSO and APSO.

\begin{tabular}{c|c|c}
\hline $\begin{array}{c}\text { Optimization } \\
\text { Method }\end{array}$ & Advantages & Disadvantages \\
PSO & $\begin{array}{c}\text { Less parameters tuning } \\
\text { Easy constraint } \\
\text { Good for multi- } \\
\text { objective optimization }\end{array}$ & $\begin{array}{c}\text { Low quality solution } \\
\text { Needs memory to update } \\
\text { velocity }\end{array}$ \\
APSO & $\begin{array}{c}\text { Very efficient } \\
\text { early convergence }\end{array}$ \\
& $\begin{array}{c}\text { High quality solution } \\
\text { Local exploitation } \\
\text { capability }\end{array}$ & $\begin{array}{c}\text { Suffers from early convergence } \\
\text { in the primary stages }\end{array}$ \\
\hline
\end{tabular}

Finally, from the Fig. 4 we can come into a conclusion that, APSO performs better than PSO in terms of average best fitness for up to 1000 PHEVs. 


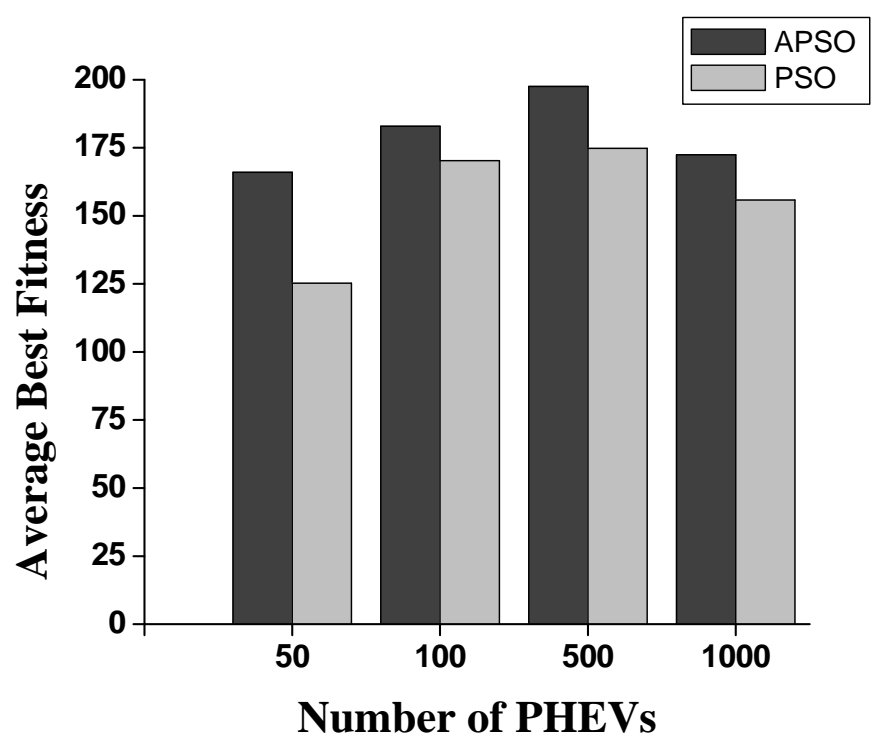

Figure 4: Average best fitness vs. no. of PHEVs (APSO and PSO).

\section{Conclusion and recommendations}

In this paper, APSO-based optimization was performed in order to optimally allocate power to each of the PHEVs entering into the charging station. A sophisticated controller will need to be designed in order to allocate power to PHEVs appropriately. For this wake, the applied algorithm in this paper is a step towards real-life implementation of such controller for PHEV Charging Infrastructures. Here, four (04) different numbers of PHEVs were considered for MATLAB Simulation and then obtained results were compared with PSO in terms of average best fitness and computational time. The success of the electrification of transportation sector solely depends on charging infrastructure. Only proper charging control and infrastructure management can assure the larger penetration of PHEVs. The researchers should try to develop efficient control mechanism for charging infrastructure in order to facilitate upcoming PHEVs penetration in highways. In future, more vehicles should be considered for intelligent power allocation strategy as well as hybrid versions of PSO should be applied to ensure higher fitness value and low computational time.

\section{Acknowledgement}

The authors would like to thank Universiti Teknologi PETRONAS (UTP) for supporting the research under UTP Graduate Assistantship (GA) scheme. 


\section{References}

[1] On certain integrals International Energy Agency (lEA), Transport, Energy and $\mathrm{CO}_{2}$-Moving Towards Sustainability, Paris, 2009.

http://www.iea.org/newsroomandevents/pressreleases/2009/october/name, 20274,en.html

[2] Holtz-Eakin, D., \& Selden, T. M., Stoking the fires? $\mathrm{CO}_{2}$ emissions and economic growth. Journal of public economics, 57(1), 85-101, 1995.

[3] S. F. Tie and C. W. Tan, A review of energy sources and energy management system in electric vehicles. Renewable and Sustainable Energy Reviews, vol. 20, pp. 82-102, 2013.

[4] Environmental assessment of plug-in hybrid electric vehicles, Volume 1: Nationwide greenhouse gas emissions, Electric Power Research. Institute (EPRI), Palo Alto, CA, Tech. Rep. 1015325, Jul. 2007.

[5] H. Lund and W. Kempton, Integration of renewable energy into the transport and electricity sectors through V2G. Energy policy, vol. 36, pp. 3578-3587, 2008.

[6] A. R. Hota, M. Juvvanapudi, and P. Bajpai, Issues and solution approaches in PHEV integration to the smart grid. Renewable and Sustainable Energy Reviews, vol. 30, pp. 217-229, 2014.

[7] Soares, J., Sousa, T., Morais, H., Vale, Z., Canizes, B., \& Silva, A. (2013). Application-Specific Modified Particle Swarm Optimization for energy resource scheduling considering vehicle-to-grid. Applied Soft Computing, 13(11), 4264-4280, 2013.

[8] W. Su and M.-Y. Chow, Computational intelligence-based energy management for a large-scale PHEV/PEV enabled municipal parking deck. Applied Energy, vol. 96, pp. 171-182, 2012.

[9] Su, W. \& Chow, M.-Y., Performance evaluation of a PHEV parking station using particle swarm optimization. In Power and Energy Society General Meeting, 2011 IEEE (pp. 1-6). IEEE, 2011.

[10] W. Su and M.-Y. Chow, Performance evaluation of an EDA-based largescale plug-in hybrid electric vehicle charging algorithm. Smart Grid, IEEE Transactions on, vol. 3, pp. 308-315, 2012.

[11] A. Shafiei and S. S. Williamson, Plug-in hybrid electric vehicle charging: Current issues and future challenges. In Vehicle Power and Propulsion Conference (VPPC), 2010 IEEE, pp. 1-8, 2010.

[12] K. Morrow, D. Karner, J. Francfort, Plug-in hybrid electric vehicle charging infrastructure review, Technical report, The Idaho National Laboratory, 2008.

[13] Investigation into the scope for the transport sector to switch to electric vehicles and plug-in hybrid vehicles. Technical report, Department for Transport, England, UK, 2008.

[14] D. Mayfield, Site Design for Electric Vehicle Charging Stations. ver. 1.0, Sustainable Transportation Strategies, Jul. 2012.

[15] G. Boyle, Renewable Electricity and the Grid: The Challenge of Variability. Earthscan Publications Ltd, 2007. 
[16] A. Hess, M. Francesco, M. Reinhardt, C. Casetti, Optimal deployment of charging stations for electric vehicular networks. In Proc. of the First Work. On Urban Net. ACM, New York, USA, pp. 1-6, 2012.

[17] Z. Sahinoglu, Z. Tao, K. H. Teo, Electric vehicles network with nomadic portable charging stations. IEEE Vehicular Technology Conf., Ottawa, Canada, pp. 1-5, Sep. 2010.

[18] Yang, Xin-She., Nature-inspired metaheuristic algorithms. Luniver press, 2010.

[19] A. E. Fergany, Accelerated Particle Swarm Optimization-based Approach to the Optimal Design of Substation Grounding Grid, PRZEGLĄD ELEKTROTECHNICZNY, Issue 07, pp. 30-34, 2013.

[20] Vasant, P., T. Ganesan, and I. Elamvazuthi, An improved PSO approach for solving non-convex optimization problems. ICT and Knowledge Engineering (ICT \& Knowledge Engineering), 2011 9th International Conference on. IEEE, 2012.

[21] Ganesan, T., Vasant P., and I. Elamvazuthy, A hybrid PSO approach for solving non-convex optimization problems. Archives of Control Sciences 22.1 (2012): 87-105.

[22] B. R. Reddy, Performance Analysis of MIMO Radar Waveform using Accelerated Particle Swarm Optimization Algorithm. arXiv preprint arXiv:1209.4015, 2012.

[23] Talatahari, S., E. Khalili, and S. M. Alavizadeh, Accelerated particle swarm for optimum design of frame structures. Mathematical Problems in Engineering, vol. 2013, Article ID 649857, 6 pp., 2013.

[24] K. Prajna, G. S. B. Rao, K. Reddy, and R. U. Maheswari, A New Dual Channel Speech Enhancement Approach Based on Accelerated Particle Swarm Optimization (APSO). International Journal of Intelligent Systems and Applications (IJISA), vol. 6, p. 1, 2014.

[25] Ganesan, T., Elamvazuthi, I., Ku Shaari, K. Z., \& Vasant, P., Swarm intelligence and gravitational search algorithm for multi-objective optimization of synthesis gas production. Applied Energy, 103, 368-374, 2013.

[26] A. Z. Mohamed, S. H. Lee, H. Y. Hsu, and N. Nath, A faster path planner using accelerated particle swarm optimization. Artificial Life and Robotics, vol. 17, pp. 233-240, 2012.

[27] Wen-Yeau Chang, The State of Charge Estimating Methods for Battery: A Review. ISRN Applied Mathematics, vol. 2013, Article ID 953792, 7 pp., 2013. 